\begin{tabular}{|c|l|}
\hline Title & Convective and Radiative heat Transfer Coefficients for the Human Body \\
\hline Author(s) & Mochida, Tohru \\
\hline Citation & 北海道大學工學部研究報告, 84, 1-11 \\
\hline Issue Date & 1977-07-11 \\
\hline Doc URL & http://hdl.handle.net/2115/41421 \\
\hline Type & bulletin (article) \\
\hline File Information & 84_1-12.pdf \\
\hline
\end{tabular}

Instructions for use 


\title{
Convective and Radiative Heat Transfer Coefficients for the Human Body
}

\author{
Tohru MOcHIDA*
}

(Received December 27, 1976)

\begin{abstract}
As a general equation to give the mean convective heat transfer coefficient for the human body, an equation which is the sum of the local convective heat transfer coefficients weighted with the skin area ratios was theoretically derived based on the heat equilibrium between man and his environment. In hot and high air velocity conditions, with the above equation derived and Hilpert's dimensionless equation of forced convection, the value of $18 \mathrm{~cm}$ was obtaind as the diameter of a man-equivalent thermal cylinder from the standpoint of heat transmission by reverse calculation. Further, by applying Oosthuizen-Madan's dimensionless equation which considers both natural and forced convective heat transfer at the same time to a cylinder of $18 \mathrm{~cm}$ in diameter, an equation which shows the convective heat transfer coefficient for the human body was proposed and compared with the values and equations of convective coefficients from earlier studies.

A radiative heat transfer coefficient and a radiant temperature with new concepts were derived by extending Gebhart's absorption factor method on reciprocal radiation exchange and by appiying it to the space between the human body and the surroundings and by linearizing from the so-called raising to the fourth power radiation law. The new radiative heat transfer coefficient is composed of the emissivity of the human surface, Stefan-Boltzmann Constant and the temperature factor and does not include the emissivity of the surrounding wall surface. On the other hand, the new mean radiant temperature is weighted with the absorption factors between the human body and its surrounding walls.
\end{abstract}

\section{Introduction}

In a steady state the metabolic heat produced in the body is lost via the pathway of convection, radiation, perspiration, respiration, ventilation under garments and external mechanical work, thus heat balance between man and his environment is maintained. When the main three heat losses, namely, convection, radiation and perspiration from the human surface, are described, some unfixed factors or unsettled values remain, although the concept is known. The surface heat transfer coefficient for the human body is one of them. The heat transfer coefficients divided into two parts, i. e., the convective and the radiative ones, especially values or equations about the convective coefficient for man have been proposed by physiologists and biological engineers. But considerable differences are seen among those actual values and proposed equations, which were obtained

* Department of Sanitary Engineering, Faculty of Engineering, Hokkaido University, Sapporo, 060, Japan. 
by experiments using subjects or derived by theoretical analyses, although it was noted that the conditions of these experiments are more or less different in each case. It appears to be quite difficult to obtain "precise" data from an expriment using a human subject who is a complicated thermal body. We will now consider the skin temperature which is fundamental when the value of heat transfer coefficient is calculated and determined. As to the method of choice of the site of the skin surface to be measured, as to how to secure the thermocouples to the skin, and also the difference among the values of mean skin temperature caused by various averaging methods, accuracy of measuring apparatus and so forth will be considered the above items have a great influence on the measurement of skin temperature and also on the definition of the heat transfer coefficient. Therefore a difference among the convective coefficient values obtained would naturally arise if they are to be calculated mainly from experimental data. Taking into consideration the physiological properties of the human body, the author will theoretically examine the convective and the radiative heat transfer coefficients for the human body from an engineering point of view and proposal of the actual values and equations regarding them will be made.

\section{Nomenclature}

$Q: \quad$ metabolic heat production, Kcal $/ \mathrm{h}$

$Q_{d}: \quad$ dry heat loss (convection and radiation), Kcal $/ \mathrm{h}$

$Q_{d i}: \quad$ dry heat loss from the body segment $i, \mathrm{Kcal} / \mathrm{h}$

$Q_{e}$ : evaporation heat loss, $\mathrm{Kcal} / \mathrm{h}$

$Q_{e i}$ : evaporation heat loss from the body segment $i, \mathrm{Kcal} / \mathrm{h}$

$Q_{s}$ : direct radiation heat between the body $s$ and the environment, $\mathrm{Kcal} / \mathrm{h}$

$Q_{s i}$ : direct radiation heat from the body $s$ to the wall $i, \mathrm{Kcal} / \mathrm{h}$

$Q_{r}$ : net rate of heat between the body and the environment due to reciprocal radiation processes, $\mathrm{Kcal} / \mathrm{h}$

$Q_{j}: \quad$ net rate of radiation heat loss from the segment $j, \mathrm{Kcal} / \mathrm{h}$

$h_{c}$ : mean convective heat transfer coefficient for $\operatorname{man}, \mathrm{Kcal} / \mathrm{m}^{2} \mathrm{~h}^{\circ} \mathrm{C}$

$h_{c i}$ : local convective heat transfer coefficient for the body segment $i$, Kcal/ $\mathrm{m}^{2} \mathrm{~h}^{\circ} \mathrm{C}$

$h_{\text {o for }}$ : forced convective heat transfer coefficient, $\mathrm{Kcal} / \mathrm{m}^{2} \mathrm{~h}^{\circ} \mathrm{C}$

$h_{r}$ : radiative heat transfer coefficient derived by using the absorption factor method, $\mathrm{Kcal} / \mathrm{m}^{2} \mathrm{~h}^{\circ} \mathrm{C}$

$h_{r i}$ : radiative heat transfer coefficient for the body segment $i$ (in this paper, $\left.h_{r} \equiv h_{r i}\right), \mathrm{Kcal} / \mathrm{m}^{2} \mathrm{~h}^{\circ} \mathrm{C}$

$\alpha_{r}$ : radiative heat transfer coefficient derived by restriction to only direct radiation exchange, $\mathrm{Kcal} / \mathrm{m}^{2} \mathrm{~h}^{\circ} \mathrm{C}$

$T_{s}:$ mean skin temperature, ${ }^{\circ} \mathrm{C}$

$T_{s i}$ : skin temperature on the body segment $i,{ }^{\circ} \mathrm{C}$

$T_{a}$ : ambient air temperature (is assumed to be equal to the radiant temperature), ${ }^{\circ} \mathrm{C}$

$T_{i}: \quad$ surface temperature of the wall $i,{ }^{\circ} \mathrm{C}$

$T_{r}$ : mean radiant temperature, ${ }^{\circ} \mathrm{C}$

$\kappa:$ modified Lewis relation, ${ }^{\circ} \mathrm{C} /(\mathrm{Kg} / \mathrm{Kg})$

$X_{s}$ : mean humidity ratio at the skin surface, $\mathrm{Kg} / \mathrm{Kg}$

$X_{s i}$ : humidity ratio at the skin surface segment $i, \mathrm{Kg} / \mathrm{Kg}$

$X_{a}:$ humidity ratio in ambient air, $\mathrm{Kg} / \mathrm{Kg}$ 
$A_{s}$ : effective skin surface area which relates to heat exchange (eflective skin area for the convection, radiation and evaporation heat loss is assumed to be equal to the whole body surface area respectively in the present paper), $\mathrm{m}^{2}$

$A_{s i}: \quad$ local skin area, $\mathrm{m}^{2}$

$S_{i}: \quad$ surface area of the wall $i, \mathrm{~m}^{2}$

$N u$ : Nusselt number (mixed=natural and forced), $N . D$.

$N u_{f o r}:$ Nusselt number (forced), N. D.

Gr: $\quad$ Grashof number, $N$. D.

Re: Reynolds number, $N . D$.

$V: \quad$ Air velocity, $\mathrm{m} / \mathrm{s}$

$\sigma: \quad$ Stefan-Boltzmann Constant, $\mathrm{Kcal} / \mathrm{m}^{2} \mathrm{~h}^{\circ} \mathrm{k}^{1}$

$\varepsilon_{s}$ : emissivity of the human surface, $N . D$.

$\varepsilon_{i}: \quad$ emissivity of the wall $i, N$. D.

$\rho: \quad$ reflectivity $(1-\varepsilon), N$. D.

$D_{i j}$ : shape factor from the wall $i$ to the wall $j, N . D$.

$\varphi_{s i}$ : angle factor from the body $s$ to the wall $i, N$. D.

$\varphi_{i s}$ : angle factor from the wall $i$ to the body $s, N . D$.

$B_{i j}$ : absorption facfor between the wall $i$ and the wall $j, N$. D.

$b_{s i}$ : absorption factor between the body $s$ and the wall $i, N . D$.

$R_{i}: \quad$ emissive power at the wall $i,\left[=\varepsilon_{i} \sigma\left(T_{i}+273\right)^{4}\right], \mathrm{Kcal} / \mathrm{m}^{2} \mathrm{~h}$

$R_{s}: \quad$ emissive power at the body $s,\left[=\varepsilon_{s} \sigma\left(T_{s}+273\right)^{4}\right]$, Kcal $/ \mathrm{m}^{2} \mathrm{~h}$

$k: \quad$ temperature factor of radiation heat exchange $=\left[\left(T_{s}+273\right)^{2}+\left(T_{i}+273\right)^{2}\right]$ $\times\left[\left(T_{s}+273\right)+\left(T_{i}+273\right)\right],{ }^{\circ} \mathrm{k}^{3}$

\section{Heat balance equation}

The metabolic energy produced in the body is mainly released by convection, radiation and perspiration. In a steady state thermal equilibrium between man and his environment is written by the following equation when heat losses by respiration, clothing ventilation and rate of external mechanical work are regarded as negligible.

$$
Q \fallingdotseq Q_{d}+Q_{e}=\left(h_{c}+h_{r}\right)\left(T_{s}-T_{a}\right) A_{s}+\kappa h_{c}\left(X_{s}-X_{a}\right) A_{s}
$$

\section{Convective heat transfer coefficient for the human body}

\section{4-1 Diameter of a man-equivalent thermal cylinder}

Since the shape of a human body is too complicated to determine the exact value of convective heat transfer coefficient, a human body must be treated in a simple form such as a cylinder ${ }^{1)}$.

Let us imagine a human body modelled and divided in such a way that the entire body may be dealt with as several parts. The human body may be considered as an assembly of several cylindrical segments. For a thermal model composed of some sections of cylinders, the sum total of heat loss from each segment is nearly equal to the metabolic rate if heat losses by respiration, clothing ventilation and rate of work accomplished are neglected.

$$
\begin{aligned}
Q & \because \sum Q_{d i}+\sum Q_{c i} \\
& =\sum\left(h_{c i}+h_{r}\right)\left(T_{s i}-T_{a}\right) A_{s i}+\sum k h_{c i}\left(X_{s i}-X_{a}\right) A_{s i}
\end{aligned}
$$

We will now assume hot environments in which the ambient air temperature (= radiant temperature) is approximately equal to the skin temperature. Under 
severe conditions the skin temperature at each segment on the body will come to be uniform as a result of physiological reaction. As there is little difference among each skin temperature and in addition between the skin temperature and the air temperature in this case, no dry heat loss by convection and radiation from the human skin occurs. As a result the human body exchanges heat with the environment by evaporation alone. Further, if it is also assumed that the humidity ratio at each site over the entire skin surface is uniform, the heat balance equation between the human body and the environment is rewritten as follows.

$$
Q \fallingdotseq \kappa h_{c}\left(X_{s}-X_{a}\right) A_{s}=\Sigma \kappa h_{c i}\left(X_{s i}-X_{a}\right) A_{s i}
$$

Further, if the above assumption is accepted, the averaged convective heat transfer coefficient for the human body is given by the following equation, since it may be regarded that the humidity ratio difference $\left(X_{s}-X_{a}\right)$ is approximately equal to $\left(X_{s i}-X_{a}\right)$,

$$
h_{c}=\sum h_{c_{j}} \frac{A_{s i}}{A_{s}}
$$

Eq (4) shows that the mean convective heat transfer coefficient is the sum of the local convective heat transfer coefficients weighted by the skin area ratios.

We can now calculate the convective coefficient for the human body by substituting the typical cylinder diameter of segments and those skin area ratios into Eq (4) and obtain the diameter of a man-equivalent cylinder from a viewpoint of convective heat transmission.

The cylinder model of a human body by Parker et al ${ }^{2)}$ was consulted in the present paper. They divided the entire body into eight parts, namely, head, neck, trunk, upper arm, forearm, finger, thigh and leg and they replaced those with the cylinders with a typical diameter. The author regards a human body as a model man who consists of six cylinders by putting together the head and the neck and by absorbing the fingers into the forearms. Each value of the typical diameter of those cylinders and the skin areas is used in round numbers with reference to the numbers by Parker et al and is shown in Table 1.

Table 1 Typical diameter of cylinder and skin area for each part of a human body

\begin{tabular}{c|c|c|c|c|c|c}
\hline & Head & Trunk & Upper arms & Forearms & Thighs & Legs \\
\hline $\begin{array}{c}\text { Diameter } \\
{[\mathrm{cm}]}\end{array}$ & 20 & 30 & 10 & 10 & 20 & 10 \\
\hline $\begin{array}{c}\text { Skin area } \\
{\left[\mathrm{m}^{2}\right]}\end{array}$ & 0.2 & 0.6 & 0.1 & $0.2^{*}$ & 0.4 & 0.3 \\
\hline
\end{tabular}

* That the skin area of forearms is twice as wide as that of upper arms is the reason why it includes that of fingers and why the fractions of the number by Parker et al are counted and over as a whole number

Using the numbers in Table 1, Hilpert's dimensionless equation ${ }^{3)}$ for forced convective heat transfer and Oosthuizen-Madan's dimensionless equation ${ }^{4}$ for mixed (natural and forced) heat transfer the typical diameter replaced with a cylinder and the value of the mean convective heat transfer coefficient for the human body are proposed.

Oosthuizen-Madan's dimensionless equation*;

$$
\frac{N u}{N u_{\text {for }}}=1+0.18\left(\frac{G r}{R e^{2}}\right)-0.011\left(\frac{G r}{R e^{2}}\right)^{2}
$$

* Since only Eq (5) was formulated as a dimensionless equation for mixed convective heat transmission, in this paper Eq (5) is used. 
Let us first use $\mathrm{Eq}(4)$ and Hilpert's equation on forced convection and apply those to such conditions as high air velocity $V=1 \mathrm{~m} / \mathrm{s}$, where natural convection is almost neglected. Thus we obtain the value of the convective heat transfer coefficient at air motion $V=1 \mathrm{~m} / \mathrm{s}$. Based on the value of the convective coefficient, $18 \mathrm{~cm}$ was obtained by a reverse calcula-

tion of a typical diameter for a man-equivalent cylinder. Atkins ${ }^{3)}$ and Stolwijk ${ }^{(6)}$ reported $14 \mathrm{~cm}$ and $16 \mathrm{~cm}$ respectively as the average body diameter when a human body is replaced with a cylinder. If Hilpert's forced convective equation is applied to Eqs 2) and 9) in Fig 3, the diameters may be reckoned backwards to about $6 \mathrm{~cm}$ and $25 \mathrm{~cm}$ respectively in the case of air velocity $V=1 \mathrm{~m} / \mathrm{s}$. The present paper treats a cylinder $18 \mathrm{~cm}$ in diameter fixed under the above condition as a man-equivalent cylinder thermal model and also from the consideration that the warm or the cold of environments does not change the dimension of an actual human body. The examination in cold or comfortable conditions will be described later. The convective heat transfer coefficient for the "skin-clothed" $18 \mathrm{~cm}$ cylinder in diameter with the characteristics of a human body will be investigated as follows.

\section{4-2 Convective heat transfer coefficient for the human body}

Natural convection coexisting with forced convection may be ignored in high air motion environments. But in slight air velocity and comfortable environments such as encountered in everyday life, since the skin temperature is generally different from the ambient air temperature, natural convection which results from the temperature difference exerts a great influence on the forced convection and it can not be ignored. The question that arises is how to choose the temperature difference as a standard of the Grashof number by which the natural convection can be evaluated. In the present paper, we will imagine a comfortable condition of an unclothed sedentary man, namely, the skin temperature $T_{s}=33.5^{\circ} \mathrm{C}$, the air temprature $T_{a}=28^{\circ} \mathrm{C}$ and calculate the Grashof number $G r$ from the difference $\Delta T=T_{s}-T_{a}=6 \operatorname{deg}\left({ }^{\circ} \mathrm{C}\right)$. The effects of the cylinder length and flow direction of air were also taken into account ${ }^{\overline{7}}$. Under this condition the Nusslt number

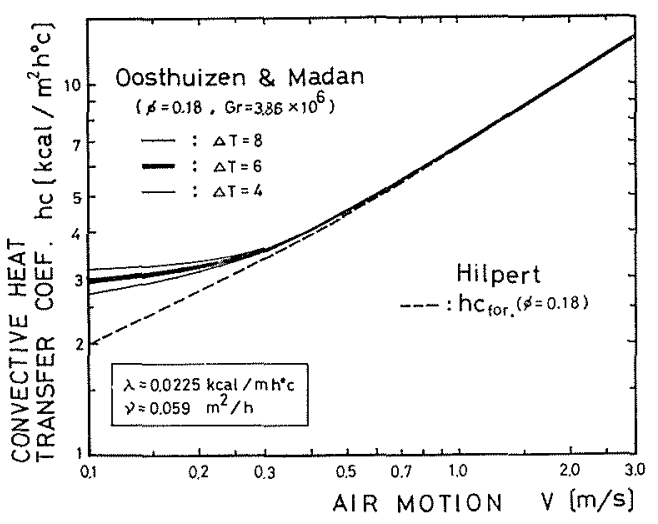

Fig. 1 Comparison of the mixed convective heat transfer coefficient and the forced convection

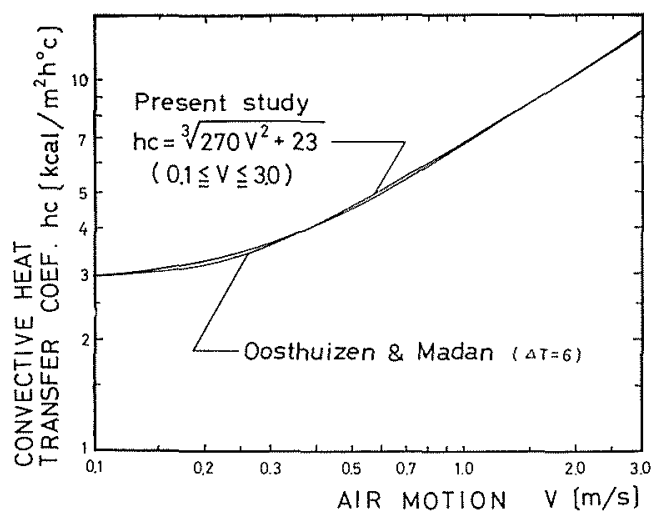

Fig. 2 Approximation curve of convective heat transfer coefficient $h_{c}$ 
$N u_{f o r}$ will be calcuulated by applying Hilpert's equation to the $18 \mathrm{~cm}$ cylinder at every air velocity.

Next, the values calculated are substituted into Oosthuizen-Madan's equation taking into consideration natural and forced convection at the same time and as a result mixed (natural and forced) convective heat transfer coefficient corresponding to each air motion can be finally obtained. The relation between the mixed convective heat transfer doefficient $h_{c}$ and the forced convection $h_{c}$ for is shown in Fig. 1. Fig. 1 shows that natural convection has a great influence on forced convection at low air motion environments.

Using Eq (4), (5) and Table 2, the mixed convective heat transfer coefficient $h_{c}$ for the man-equivalent cylinder is closely simulated by the following equation and the locus is shown in Fig. 2.

$$
h_{c}=\sqrt[3]{270 V^{2}+23} \quad(0.1 \leqq V \leqq 3.0)
$$

\section{4-3 Comparison of the convective heat transfer coefficients}

Physiologists and biological engineers have proposed the convective heat transfer coefficients regarding the human body based on theoretical analyses or experiments using human subjects.

The proposed equations 1) 9) in Fig. 3 by earlier studies are compared with the present locus in Fig. 3, although the experiment conditions namely the temper ature range, posture conditions and so forth from which they were derived show a considerable variation,

Eq (6), which is obtained based on the considerations under the condition of hot environments and then by extending to comfortable conditions rationally, lies among Eqs 1) -9) in Fig. 3. From the standpoint of convective heat transfer, a cylinder $18 \mathrm{~cm}$ in diameter may be regarded as a model human body. As a matter of course, strictly speaking, the convection phenomena in a sedentary state are different from those at standing one. Further, although a sedentary man may resemble a sphere or he may be a shape between a sphere and a cylinder rather than a mere cylinder, the cylinder $18 \mathrm{~cm}$ in diameter as derived above will be dealt with as a man-equivalent thermal model in the present paper.

Next, let us think of the convective heat transfer coefficient derived from a heat balance equation under comfortable or cold conditions. If a steady state such as a cold environment is maintained without heat production by shivering or under comfort conditions, the heat loss by perspiration is approximately onefourth of internal heat production. We can obtain the following equation by dealing with the heat loss with perspiration as a constant.

$$
\begin{gathered}
Q-Q_{c}=Q-\sum Q_{c i} \\
=\left(h_{c}+h_{r}\right)\left(T_{s}-T_{a}\right) A_{s}=\sum\left(h_{c i}+h_{r i}\right)\left(T_{s i}-T_{a}\right) A_{s i}
\end{gathered}
$$

Convective heat transfer coefficient $h_{c}$, radiative heat transfer coefficient $h_{r}$ and mean skin temperature $T_{s}$ will be obtained as follows by solving the identical equation (8).

$$
\begin{gathered}
h_{c}=\sum h_{c i} \frac{A_{s i}}{A_{s}} \\
h_{r}=\sum h_{r i} \frac{A_{s i}}{A_{s}} \\
T_{s}=\sum\left(\frac{h_{c i}+h_{r i}}{h_{c}+h_{r}}\right)\left(\frac{A_{s i}}{A_{s}}\right) T_{s i}
\end{gathered}
$$

The form of Eq (4) derived under hot conditions and that of $\mathrm{Eq}$ (9) under cold or comfortable conditions are all the same in the literature, but there is a 


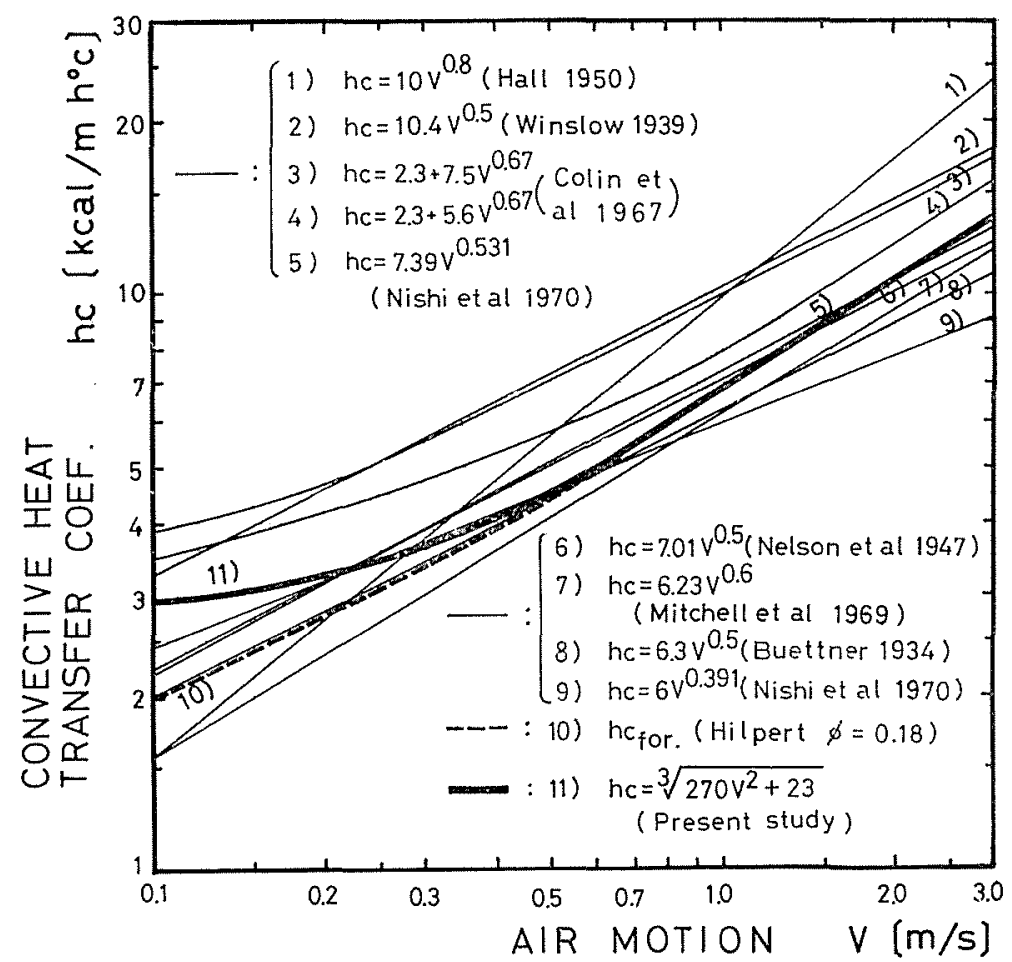

Fig. 3 Comparison of various convective heat transfer coefficients

1) : J. Hall, Copper manikin regional heat loss and cooling constants, Meno. Rept. MCREXD-696-1058, Wright-Patterson Air Force Base, Ohio, 1959

2) : C-E. A. Winslow, A. P. Gagze and L. P. Herrington, The influence of air movement upot heat losses fro.n the clothed human body, Am. J. Physiol. 127, p. 595, 1939

3),4): J. Colin and Y. Houdas, Experimental determination of coefficient of heat exchanges by convection of human body, J. Appl. Phys!ol, 22, p. 31, 1967

5), 9): Y. Nishi and A. P. Gagge, Direct evaluation of convective heat transfer coefficient by naphthalene sublimation, J. appl. Physiol. 29, p. 830,1970

6) : N. Nelson, L, W. Eichna, S. M. Horvath. W. B. Shelley and T, F. Hatch, Thermal ex change of man at high temperature, A n. J. Physiol. 151, p. 626, 1947

7) : D. Mitchell, C. H. Wyndham, A. J. Vermulen, T. Hodgson, A R. Atkins and H. S. Hof neyr Radiant and convective heat transfer of nude men in dry air, J. Appl. Physiol. 26, p. 171, 1969

8) : K. Buettner, Die Wärmeübartraging durch Leitung und Konvektion verdünstung und Strahlung in Bioklimatologie und Matzorologie, Veröffentlichungen des Praussischen meteorologischen Instituts Abwandlungen 10 No.5, 1934

great difference in the contents between both the convective coefficients. $h_{c}$ in Eq (4) has only forced convective heat transfer coefficient in it, on the other hand, $h_{c}$ in Eq (9) consists of natural and forced convective heat transfer coefficients. If cylinder diameters could be calculated backwards from Eq (4) and Eq (9) respctively, the comparison and examination of these two values may be done directly. But it is difficult to divide $h_{c}$ in $\mathrm{Eq}(9)$ into natural convective coefficient and the forced convective coefficient. Under the considerations that in high air motion environments the value of $h_{c}$ in Eq (4) will approximately agree with that of $h_{c}$ in $\mathrm{Eq}(9)$ since natural convection is almost ignored and that at low air movement the forced convective coefficient in $\mathrm{Eq} \mathrm{(9)} \mathrm{would} \mathrm{agree} \mathrm{with}$ the extention of $\mathrm{Eq}(4)$, the cylinder $18 \mathrm{~cm}$ in diameter will be treated as a model human subject.

The mean skin temperature $T_{s}$ in Eq (11) shows a new one ${ }^{8,9), 10)}$ weighted by the ratios of heat transfer coefficient and skin area. This is different from the mean skin temperature weighted by skin area ratios alone. 


\section{Radiative heat transfer coefficient for the human body}

\section{5-1 Radiative heat transfer coefficient derived based on a direct radiation exchange}

When a man is enclosed with walls which have equal emissivity but have different surface temperatures, the radiant energy balance is expressed as follows by only a direct radiation exchange if the reciprocal radiation is neglected.

$$
\begin{aligned}
Q_{s} & =\sum Q_{s i}=\sum \varepsilon_{i} \varepsilon_{s} \sigma\left\{\left(T_{s}+273\right)^{4}-\left(T_{i}+273\right)^{4}\right\} \varphi_{s i} A_{s} \\
& =\varepsilon_{i} \varepsilon_{s} \sigma k \sum\left(\varphi_{s i} T_{s}-\varphi_{s i} T_{i}\right) A_{s} \\
& =\alpha_{r}\left(T_{s}-\sum \varphi_{s i} T_{i}\right) A_{s}
\end{aligned}
$$

The radiative heat transfer coefficient $\alpha_{r}$ as denoted in Eq (12) is defined by the following equation in this case ${ }^{11}$.

$$
\alpha_{r}=\varepsilon_{i} \varepsilon_{s} \sigma k
$$

What is more important is that $\sum \varphi_{s i} T_{i}$ expresses a kind of mean radiant temperature ${ }^{i)}$ weighted by angle factors between man and the surrounding walls.

\section{5-2 Radiative heat transfer - Gebhart's absorption factor}

In a closed space, regarding the radiant heat exchage between the various walls, Gebhart using the absorption factor expressed the results by the so-called raising to the fourth power radiation law.

$$
\begin{aligned}
& Q_{j}=R_{j} S_{j}-B_{1 j} R_{1} S_{1}-B_{2 j} R_{2} S_{2}-\cdots-B_{j j} R_{j} S_{j}-\cdots \\
& -B_{n j} R_{n} S_{n} \\
& =R_{j} S_{j}-\sum B_{i j} R_{i} S_{i} \\
& \emptyset_{n j} \varepsilon_{j}+\emptyset_{n 1} \rho_{1} B_{1 j}+\cdots+\left(\Phi_{m n} \rho_{n}-1\right) B_{n j}=0
\end{aligned}
$$

\section{5-3 Application of absorption factor to the human body and the} surrounding walls

The absorption factor defined by Gebhart ${ }^{12)}$ is mainly a means of expression of radiation heat exchange between walls and moreover it is governed by a raising to the fourth power radiation law.

The author extended this calculating method and applied it to the space between the human body and the walls. The human body in this case is treated as a minimal element, that is, the element does not hinder radiation exchange between the walls themselves. In other words, since the element does not have a dimension, it is not a mere dot but the direction of radiation exchange alone may be considered. Based on the above considerations, an attempt is made to linearize by raising the radiation to the fourth power and here the radiative heat transfer coefficient and mean radiant temperature under a new concept are discussed.

Let us assume a human body $s$ at an arbitrary position in a closed space. Eq (14) in which considerations are made for the reciprocal radiation exchange in the give and take of the radiation heat between various walls may be expressed by the following equation if applied between the human body and the surrounding walls.

$$
Q_{r}=R_{s} A_{s}-\sum b_{i s} R_{i} S_{i}
$$

In the above equation, since $R_{s}=\varepsilon_{s} \sigma\left(T_{s}+273\right)^{4}, R_{i}=\varepsilon_{i} \sigma\left(T_{i}+273\right)^{4}, \sum b_{s i}=1$ from the special feature of the absorption factor and $b_{s i} \varepsilon_{s} A_{s}=b_{i s} \varepsilon_{i} S_{i}$, Eq (16) may be transformed to $\mathrm{Eq}(17)$. 


$$
\begin{aligned}
Q_{r} & =\varepsilon_{s} \sigma\left(T_{s}+273\right)^{4} A_{s}-\sum b_{i s} \varepsilon_{i} \sigma\left(T_{i}+273\right)^{4} S_{i} \\
& =\sum b_{s i} \varepsilon_{s} \sigma\left(T_{s}+273\right)^{4} A_{s}-\sum b_{i s} \varepsilon_{i} \sigma\left(T_{i}+273\right)^{4} S_{i} \\
& =\sum \sigma_{v_{i}} \varepsilon_{s} \sigma\left(T_{s}+273\right)^{4} A_{s}-\sum b_{s i} \varepsilon_{s} \sigma\left(T_{i}+273\right)^{4} A_{s} \\
& =\sum b_{s i} \varepsilon_{s} \sigma\left\{\left(T_{s}+273\right)^{4}-\left(T_{i}+273\right)^{4}\right\} A_{s} \\
& =\varepsilon_{s} \sigma k\left(\sum b_{s i} T_{s}-\sum b_{s i} T_{i}\right) A_{s} \\
& =h_{r}\left(T_{s}-\sum b_{s i} T_{i}\right) A_{s}
\end{aligned}
$$

\section{5-4 Radiative heat transîer coefficient derived from using}

\section{absorption factor}

The temperature factor $k$ in Eq (17) is as shown in Fig. 4. Since the change is gradual, if the temperature range is limited, it becomes possible to regard it as a constant.

Further, in radiation heat exchange in an ordinary room, as long waves are mainly involved, objects generally found in the room may be considered as gray bodies, and in addition the skin of a human body and garment surface would have an emissivity close to that of a black body. Therefore, when the temperature range is assumed in our current living conditions,

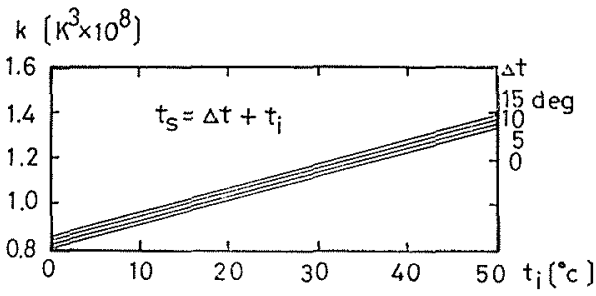

Fig. 4 Change of temperature factor $k$ and if $\varepsilon_{s} \sigma k$ in $\mathrm{Eq}(17)$ is collectively treated as a constant, the radiative heat transfer coefficient $h_{r}$ may be defined by the following equation ${ }^{139}$.

$$
h_{r}=\varepsilon_{s} s k
$$

If the following values are substituted into $\mathrm{Eq}(18)$ as concrete values in a daily life, the radiative heat transfer cofficient $h_{r}, h_{r}=4.8 \mathrm{Kcal} / \mathrm{m}^{2} \mathrm{~h}^{\circ} \mathrm{C}$ can be obtained.

The values substituted;

$$
\begin{aligned}
& \varepsilon_{s}=0.95 \mathrm{~N} . \mathrm{D} . \\
& \sigma=4.88 \times 10^{-\mathrm{s}} \mathrm{Kcal} / \mathrm{m}^{2} \mathrm{~h}^{\circ} \mathrm{K}^{*} \\
& k=1.05 \times 10^{5} \mathrm{~K}^{\circ}
\end{aligned}
$$

Naturally beyond the above range defined appropriate values must be substituted.

Moreover, $\sum b_{s i} T_{i}$ in Eq (17) expresses a kind of mean radiant temperature ${ }^{132}$ and it is defined by a weighted mean of the temperatures of the surrounding surface with absorption factor which includes angle factor. In order to differentiate the mean radiant temperature weighted by angle factor or by area ratio and to avoid confusion brought about by the difference in averaging, $\sum b_{s i} T_{i}$ will be refered to in this paper as "Environmental Radiant Temperature".

The characteristic features of the environmental radiant temperature weighted by the absorption factors are not only made for the geometric position but also for the emissivity of each wall surface in the absorption factor $b_{s i}$. On the contrary, according to the expression method based on a direct radiation exchange, the emissivity of the wall is contained in the radiative heat transfer coefficient $\alpha_{r}$. When $h_{r}$ in $\mathrm{Eq}$ (18) is compared with $\alpha_{r}$ in $\mathrm{Eq}(13), h_{r}$ has only the emissivity of the human surface but $\alpha_{r}$ in itself includes both the emissivities of the surrounding wall and the human body surface. It follows that if each wall which encloses a human body is approximately a black body and moreover when all the emissivities of enclosing walls are equal or nearly equal, the difference between the values $h_{r}$ and $\alpha$, may be almost neglected. But it also follows that 
in the case of a special room made of various walls with the great difference among those emissivities, another emissivity $\varepsilon_{i}^{*}$ by some means of averaging must be used. Otherwise errors will arise.

\section{Conclusions}

1. As an equation which gives the mean convective heat transfer coefficient for the human body, Eq (4) was theoretically derived. Eq (4) shows that the mean convective coefficient is the sum total of the local convective coefficients weighted with each skin area ratio. By using this equation, the diameter of a man-equivalent thermal cylinder model was set at $18 \mathrm{~cm}$ and moreover by applying it to the dimensionless equations by Hilpert and by Oosthuizen et al, convective heat transfer coefficient with natural and forced convection taken into cousiderations at the same time was calculated. Based on the values calculated at each air velocity, an approximation curve Eq (6) which expresses mean convective heat transfer coefficient for the human body was obtained and compared with the convective coefficient equations proposed by the earlier workers. The present convective heat transfer coefficient shows a mean value among the loci by earlier studies on analyses and experiments.

Convective heat transfer coefficient

for the human body;

$$
h_{c}=\sqrt[3]{270 V^{2}+23} \quad(0.1 \leqq V \leqq 3.0)
$$

2. The absorption factor method by Gebhart which is one of the expressive means regarding reciprocal radiation heat exchange was extended and applied to the space between a human body and its surroundings. By limiting the temperature range and linearizing by raising the radiation to the fourth power of absolute temperature, a new radiative heat transfer coefficient and a kind of mean radiant temperature - Environmental Radiant Temperature - were obtained.

The radiative coefficient consists of the emissivity of the human surface, Stefan-Boltzmann Constant and the temperature factor, and the emissivity of the surrounding wall is not included in it.

The environmental radiant temperature is averaged and weighted by the absorption factors between the human body and the surrounding walls.

Mean radiant temperature weighted by the absorption factors between the human body and the surrounding walls - Environmental Radiant Temperature;

$$
T_{r}=\sum b_{s i} T_{i}
$$

Radiative heat transfer coefficient;

$$
h_{r}=\varepsilon_{s} \sigma k
$$

\section{References}

1) T. Mochida; An examination on convective heat transfer coefficient for the human body, A. I. J. annual meeting, 1976, p. 443.

2) A. Parker, D. A. Ekberg, D. J. Withey et al; Atmosphere selection and control for manned space stations, General Electric Co., Missile and space Div., Valley Forge, Pa., Presented at the International Symposium for manned space Stations in Munch, 1965 (Cited by Ningen-Kankyokei, Ningen to Gijutsusha. 1972, p. 185, Written in Japanese).

3) W. H. McAdams; Heat Transmission, McGraw-Hill, Kogakusha, 1962, p. 260.

4) P. H. Oosthuizen and S. Madan; Combined convective heat transfer from horizontal cylinder in air, ASME Trans., 1970, p. 194. 
5) A. R. Atkins and C. H. Wyndham; A study of temperature regulation in the human body with aid of an analogue computer, Pflugers Arch., Vol. 307, 1969, p. 104.

6) J. A. J. Stolwijk; Unpublished lecture, Pierce Foundation Lab., Yale Univ., U. S. A., 1962 (Cited by Milsum, Seitaichoosetukei no Kaiseki, Koronasha, 1970, p. 72, translated into Japanese).

7) K. Ibamoto and Y. Nishi; Thermal sensation analysis and its application to air-conditioning, Bulletin of the Faculty of Engineering, Hokkaido Univ., Japan, No. 46, 1968 , p. 73.

8) Y. Nishi and A. P. Gagge; Direct evaluation of convective heat transfer coefficient by naphthalene sublimation, Journal of Applied Physiology, Vol. 29, 1970, p. 830.

9) T. Mochida and Y. Nishi; Mean skin temperature taken into consideration local heat transfer coefficient, SHASE annual meeting, 1971, p. 95.

10) T. Mochida; An examination on mean skin temperature from an engineering method, SHASE winter meeting, 1972, p. 5.

11) H. Saitoh; Kenchiku kikou, Kyoritsu shuppansha, 1974, p. 15

12) B. Gebhart; A new method for calculating radiant exchange, ASHRAE Trans., Vo1. 65, 1959, p. 321.

13) T. Mochida and K. Ibamoto; A study on evaluation of the thermal radiation effect - Mean radiant temperature weighted with the absorption factor, Memoirs of the Faculty of Engineering, Hokkaido Univ., Japan, Vol. XIX, No.64, 1976 p. 1. 